\title{
Teacher Education Program (B. Ed) in SAARC Countries
}

\author{
Munir Ahmed \\ Doctoral Research Scholar, University of Education \\ College Road, Township, Lahore Pakistan
}

\begin{abstract}
Muhammad Azeem (Corresponding Author)
Assessment Expert, Punjab Education Assessment System (PEAS)

University of Education, College Road, Township Lahore, Pakistan
\end{abstract}

Professor Dr. Ibrahim Khalid

University of Education, College Road, Township, Lahore Pakistan

Professor Dr. Irshad Ahmad Farrukh

Secretary at National Accreditation Council for Teacher Education (NACTE)

Dr. Fazal Ahmed

Ex-US AID program Coordinator \& Founder Director of Iqra University

Balochistan Campus -Pakistan

Mr. Shabbir Ahmed

M.Phil Research Scholar, University of Education

College Road, Township, Lahore Pakistan

Received: January 20, 2012 Accepted: March 05, 2012 DOI: 10.5296/jpag.v2i1.1606 


\section{Abstract}

The objective of the study was to evaluate the present Pre-service Elementary Teacher Education Programs (B. Ed \& equivalents) of SAARC Countries to reveal innovative ideas, which may be adopted and adapted in other countries including Pakistan. Reference books, journals, research papers, Encyclopedias of education, yearbooks, national educational policies, internet and such other resources were consulted to have an insight of these nations, their system of education and to retrieve salient features of a good Pre-service Elementary Teacher education program. Questionnaire named as "Questionnaire for Elementary Teacher Education program evaluation" was prepared, preened after pilot study at provincial capitals of Pakistan and presented to a team of local and foreign experts. Semi-structured interviews were also conducted to increase the quality and quantity of responses. In the light of high majority opinions criterion component were finalized. These components in the form of question were sent to the SAARC countries through the relevant Embassies, graduate facilitators, who on my behalf collected data. Collected data was sorted out and matched with the already developed criteria. Result revealed that Indian system of Teacher Education matches the criteria most. Pakistan has many mismatches but Elementary Teacher Education Program offered by the University of Education, Lahore and its associated colleges is bridging this gap successfully. Bhutan, Bangladesh and Maldives are showing improvements. The experiments of Sri Lanka \& Nepal have many lessons to learn.

Keywords: SAARC Countries, Teachers' education, Elementary education

\section{Introduction}

Elementary Education, as per article 28 of the UN convention on the rights of the children (CRC) and Dakar Declaration (2000), is the responsibility of the state. Its (Her) schools should accommodate all children regardless of their physical, intellectual, social, emotional, linguistic and other conditions. However, Pakistan's low literacy rate (46), nominal expenditure on education (less than $2.6 \%$ of the GDP), static position on human development ranking (134-136) during (1995-2008) shows that we are lagging far behind to fulfil the requirements. "Contrary to improvement, conditions became worst with the time". It was mentioned by Javed Ashraf Qazi, Ex-Federal Minister of Education, in the opening session of Educational Conference at National Library Islamabad (May, 2006). There he, included Pakistan in the three least developed countries of the world as for as education is concerned. According to the experts, the plight position of education is due to teacher and their poor education. National Conference on Teacher education( 2005) organized by IED (Institute of Education Development) identified teacher, their training, available facilities, associated policies and their implementation as the causes of adverse situation. The conference concluded that current Teacher Education in Pakistan was guided by a mechanistic approach that "produced technicians rather than reflective, reflexive and critical practitioners" (Memon Muhammad, 2005). The same was concluded by APEID (The Asia-Pacific Program of Educational Innovation for Development) \& different intelligentsias in their times. Most teachers lack enthusiasm, motivation, dedication and preparedness. Unattractive salary scales, 
limited prospects of promotion and low social status proves a deterrent to high calibre teacher (Planning Commission, 1989). The quality of pre-service training for most of the teacher training institutions is outmoded and low as compared to international standard. There is urgent need to update the knowledge and skills of teacher education. (Planning Commission June, 1994)

It is recommended that teacher education program must cater to the fast emerging need of the country. The curriculum contents, methods, evaluation of teaching and other teacher related resources must be enriched regularly (Imran Ibrahim, (1999-2000). Training institutions have not only budgetary and financial problem but also of imbalance courses of academic, content of school curriculum, teaching methods, teaching practices and curricular activities. Textbooks of teacher education are poor and neither teacher's guide nor supplementary material is available. Exam system is highly defective and there is acute shortage of facilities. (National Education Policy, 1998-2010)

Bhutan is only and lonely partner of Pakistan in SAARC nations, who spends less than $3 \%$ of GDP on education. Afghanistan, new member, is the only one in whole Asia and South Asia, whose ranking in education is lower to us. (Iqbal, 1999)

Many studies in Pakistan explored the shortcomings of our system and suggested the remedies. British Council's survey of teacher education suggested that the teacher training system required substantial expansion and quality improvement. ADB sector study on education identified the shortage of trained teachers as major constraint on improving education

Warwick and Reimers (1991) found in an independent study that the content knowledge of Pre-Service and in- Service teachers in Pakistan is low (Warwick, Donald P. and Fernando M. Reimers, 1991). Similarly MSU-SAP (1995) found negligible difference in performance, when Teachers with or without Pre- Service Training were tested on content knowledge (UNESCO 2006).

UN Inter -Agency Mission on basic Education (1995) found that present Teacher Education (1995) does not appear to improve the quality of instruction and it was proposed that teacher should be provided with job stability and training especially in modern teaching methods.

Studies in Pakistan show that there is no significant difference in teaching practices of PTC teachers and untrained teachers or between PTC graduated from different systems. (Mahbub-ul-Haq, Khadija Haq, 1998)

Khan (2004) found that approximately $75 \%$ of teachers are provided with outdated and irrelevant training through the PTC or CT (Khan, Sughra Choudhry 2004).

Moreover, the Diploma in Education Program introduced across Pakistan by the Technical Panel on Teacher Education to replace PTC/CT has not been evaluated as to date. Similarly B. Ed and M. Ed extended program were not even tested (UNESCO and USAID 2005).

Like Pakistan, many nations have suffered from these qualitative and quantitative problems of teacher education. They, through research, understood the problems and tried different 


\section{Macrothink}

options to overcome them. About twenty five (25) years ago, an Indian intellectual said, "the main deterrents to the development of an efficient Teacher Education are: Artificiality in courses, in-effective methods of teaching, poor academic background, no impact on school practices, less emphasis on development of professional attitude, lack of proper facilities, imbalance in demand and supply, little interaction with the main academic stream, inadequate bases of empirical research, no in-built system for the professional development and inadequate financial provision." (T.S. Sodhi 1983,)

The Government of India took it very seriously and a council of Teacher Education came into being in 1986. It poured on research, framed the norms and standards of Teacher Education Programs, and initiated the Accreditation system for the Teacher Education. This all improved the system and led it to glory. At present, India is the only country which is comparatively in better position.

Bhutan to accommodate its culture and identity parted from Delhi. Maldives carved out its own program of Teacher Education. Bangladesh and Sri Lanka had adopted innovative, cluster-type, in-service training programs to transform her teacher to Quality teacher.

\section{Objectives of the Study}

Following are objectives of study

1. To analyze the Teaching practice system.

2. To analyze the evaluation system.

3. To make recommendations for improvement of elementary Teacher Education program of Pakistan.

The study has been delimited to the following aspects of Pre-Service Elementary Teacher Education programs of SAARC Countries:
A: Admission criteria
B: Admission Procedure.
C: Duration of Teacher Education
D: Curriculum (courses prescribed for B. Ed \& equivalent Program of Elementary

Teacher Education, their duration, human and material resources availability for its successful implementation)

E: Evaluation System.

F: System of Teaching Practice. 


\section{Instrumentation}

Questionnaire named as "Questionnaire for Elementary Teacher Education program evaluation" as tool of research is developed. The Questionnaire has four parts as per objectives of the study. Each part is associated with the specific category of the person working in the Elementary Teacher education set up. So as per specialty of the staff, specific part is used to gather up-to -date information from the concerned persons associated with the colleges, Institutes and University's Departments of Elementary Teacher Education in the SAARC Countries. It reduced the workload of respondents and researcher remained successful in receiving the answers from for off territory.

\section{Data Collection, Coding, Entry and Analysis}

Questionnaire for Elementary Teacher Education Program Evaluation was dispatched through Embassies of SAARC Countries at UAE. It was followed by the visit of Facilitators to the concerned countries, who were the graduate employees of these countries at UAE, to collect up-to-date information. Some Countries, officials direct the researcher to the resources and resource persons. These officers belong to the places where physical visits were hazardous. Letters were written to UNESCO Bangkok, Library of Congress for assistance. They pointed out many sites and resources that helped to gain the relevant information. Telephonic conversation was also made with many concerned individuals across the globe, when and where required to make the project worthy. Questionnaire was also e-mailed to concerned individuals, departments, associations and some foundations like STF (SAARC Teacher Federation) and FOSWAL (Foundation of SAARC Writer and Literature). Some international organizations like B.B.C, FIA, UNESCO, UNICEF, OECD, ADB, WORLD Bank, were thoroughly probed to gain an insight and latest reports about the subject. The documents concerning the entry requirements, admission criteria and its procedure, curricula and mode of its delivery system of teaching practice and evaluation like prospectus, syllabus, Annual Calendar, Timetable have been studied in detail. Exam results and policies as posted on the related sites and presented in the concerned documents of the Elementary Teacher Education Colleges, Institutes and University's department of Education have also gone through to have a better understanding of the system. Each and every step of the whole research was constantly checked, preened and improved. The received answers (176) out of 250 distributed were tabulated and percentage frequencies were found out. These frequencies were grouped into high majority (66\% or above) \& simple majority (less than $66 \%$ ). Comparison of the individual country system with the Validated Evaluation Criteria leads to coherence level. All matched and mismatched items had been noted and presented as criteria followed and criteria not followed points. Salient features of the individual country's teacher education program, received through multiple resources, were placed against the traits selected by a high majority. Matched and mismatched were taken into consideration to determine the status of the individual countries elementary teacher education program. Matched were mentioned as $=\mathrm{Y}$, mismatched as $=\mathrm{N}$, Component not incorporated $=$ No and NA represented the non availability of information. The sums of the points indicated the status of the individual program. 


\section{Macrothink

\section{Findings}

Findings are categorized according to the objectives of the study;

\subsection{Admission Criteria}

1. All countries fix the age for admission as 25 years except Sri-Lanka

2. Minimum 50\% scores for application submission is recommended by experts but Pakistan, Nepal and Bangladesh invite 45\% score holders . Maldives manage low achiever through bridging program

3. Negative preference to age seniority is given by all but Sri Lanka and Maldives gives it a positive preference.

4. All countries focus more on fresh candidates except Sri Lanka and Maldives

5. All countries prefer extra qualification within the set age range

6. Bhutan and India cent percent follow admission Criteria.

\subsection{Admission Procedure}

7. Salient components like aptitude test, interview, written entrance test, were not rewarded by Maldives, Nepal and Pakistan but India other did

8. Pakistan is the only one, who not test language and numeric competencies at the time of admission

9. Most of the countries except Pakistan \& Nepal follow the ten indicators for admission procedure set by researcher and approved by experts.

10. Pakistan and Bangladesh do not have any central test

11. Nepal negates interview, aptitude test and kinship

12. Bangladesh does not have any central test but it does have an internal entrance test

13. Maldives has no minority, so there is no fix seat for this.

\subsection{Program's constituents \& their durations}

14. Program's total duration is different in different countries. India has allotted the maximum per year time whereas Maldives, Nepal and Bangladesh has allotted 
minimum per year time in this regard.

15. Time for teaching practice is different in different countries. Normally allotted time is 40 working days. All try to supplement its short duration with apprenticeship of appropriate duration so practical part becomes almost equal to $25 \%$. Similarly some allot high score or credit points.

16. Maldives has allotted a year for teaching practice so no apprenticeship. Bangladesh however has no apprenticeship and less teaching practice session.

17. In all countries, general trend is to give more and more time to theoretical part .Bangladesh, Nepal and Sri-Lanka fall in this category

18. All countries also prioritize pedagogical/Professional component as for as time is concerned.

19. Enhancement of foundation component's time is seen in Bhutan and Sri-Lanka

20. India \& Nepal give less time to General Academic component but it is supplemented by selecting special subjects in the stage specialization category

21. India has not included English and local language in the curricula at Bachelor of Education level. Students, however, may adopt these subjects in stage specialization.

22. All SAARC countries considered and thus introduced MS-office (Word / Power Point and Excel) in their teacher education program but in India, it is taken as optional. Their students already attain this competency in the lower grades

23. Sri Lanka supersedes other in giving importance to moral education.

24. Bhutan, Maldives and Pakistan lay stress to stage specialization while India strengthened this by mixing this with the professional part.

25. India, unlike others produces the subject specialists. It provides more time for concentration to stage specialization and professionalism

\subsection{Quality of Human Resources to implement the Curricula}

26. In all countries, academic qualification of faculty is appropriate

27. Professional qualification of Bhutan's, Maldives and Pakistani faculty is low

28. Qualification of Maldivian \& Pakistani's Principals is low. 


\section{Macrothink \\ Journal of Public Administration and Governance ISSN 2161-7104 2012, Vol. 2, No. 1}

29. Post graduate faculty percentage is low in Bhutan, Bangladesh, Maldives and Pakistan

30. Proportion of trained faculty in Tribhuvan University-Nepal and Maldives College of higher education is lower than recommended by experts.

\subsection{Quality of Material Resources to implement the Curricula}

31. Textual and supplementary material availability is not appropriate in Maldives, Nepal, Bangladesh and Pakistan

32. Except India ,Maldives and Pakistan, there is scarcity of resources in language, computer and science lab.

\subsection{Revision , Renovation , language and legislation of Curricula}

33. Historically Curriculum revision process is down in Bangladesh, Nepal and Pakistan but in the last five years there is at least one modification, recasting and development.

34. Historically Curriculum revision process is up to the mark in India, Bhutan and Sri-Lanka.

35. Operational medium of instruction is mother tongue in Sri-Lanka ,Maldives, Nepal, Bangladesh and Pakistan, but India and Bhutan adopted English language as a medium of instruction

36. Although, all have Accreditation council that provides norms and standards yet their life span is different. In Pakistan, it is established in 2006.

\subsection{Quantitative Aspects of Teaching practice}

37. Daily allotted and actual working hour of pupil Teacher in India are more than criteria and in other countries it is either about at par or lower than that.

38. Time wise Teaching Practice is conducted at an appropriate time in all the SAARC Countries

39. Lab schools are available in Bhutan, Maldives \& Sri-Lankan institutes located in capital. Other countries are deprived of them.

40. Number of students, allotted to Supervisors, is, normally, more than recommended 


\section{Macrothink

except Bhutan, where it is approximately 8 .

41. Minimum time spent by supervisor in observation session is low in Nepal \& Bangladesh.

\subsection{Qualitative Aspects of Teaching practice}

42. Supervisors are normally non recommended official except in India and Bangladesh

43. Activities assigned to supervisor are not properly fulfilled in any country

44. In all SAARC countries, subject teacher delivers model lesson.

45. In all SAARC countries, teachers assist students in model lesson preparation.

46. Throughout the region, teachers give feedback in writing comments when pupil teacher practice teaching.

47. Use of check list is almost vanished throughout the region.

48. No criterion is in practice throughout the SAARC Countries.

49. There is, in actual, no sense of counseling session and follow up programme, in any SAARC country, off and on its implementation is seen in India but in other places, it is much below the criteria

50. In India ,we also see off and on the use of clinical approach and implementation of criteria

51. Almost all countries are lagging behind in the implementation of what makes the teaching practice great.

\subsection{Legal bindings to appear in the examination}

52 All countries obey attendance binding but Bangladesh relaxes the students in attendance regulation.

\subsection{Quantitative Aspects of Evaluation}

53 All follow the criteria as for as per subject minimum number of allotted project, assignment, term paper and presentation are concerned.

\subsection{Qualitative Aspects of Evaluation}


54 Analysis of exam papers revealed that cramming was rejected at B. Ed level in university of education but promoted in Punjab University at the same level

55 In all countries, reasonable score is allotted to oral examination.

56 Bhutan follows objective style question more than others. India \& Pakistan (University of Education and its affiliated institutes but not the University of Punjab) have much balanced paper to promote intellectualism and creativity.

57 All try to bow down the selected study by reducing choices and spreading the paper over the whole curricula. Bangladesh provides choice more than required like Pakistan' previous system of Punjab University.( which provided $100 \%$ choice)

\section{Conclusions}

Following conclusions were drawn from the findings mentioned above;

Bhutan and India are the best as they $100 \%$ follow the admission criteria. Bangladesh, Maldives and Pakistan are the worst in it. Under present criteria, Maldives and Sri- Lanka scored less due to their policy of giving preference to serving senior students otherwise their status stands with India and Bhutan. Bangladesh, Nepal and Pakistan hold the central position.

Most of the countries fix 25 years as age range for admission. Within this range, they prefer extra Qualified, fresh graduates. In case of tie, age wise younger, session wise fresher and score wise better candidate was the first choice.

Regarding cut-off score, Bangladesh and Pakistan have fixed $45 \%$ while India 50\%. Bhutan and Nepal's case is decided by Ministry of education through demand and supply statement. Bangladesh and Pakistan need many teachers among SAARC states. That may be the reason of keeping low profile of cut- off score.

Procedure wise India supersedes the SAARC countries set up followed by Bhutan and Sri -Lanka. Pakistan deviate the most, followed by Nepal and Bangladesh. Regard \& reward for previous employment, co curricular activities and minorities are common to all SAARC countries.

Central written test, introduced by India and adopted by Bhutan, is the excellent innovation in SAARC scenario. They test in it almost everything that ought to be tested for best selection. Linguistic, Numeric, Aesthetic, Arithmetic capabilities and aptitude for the profession are tested under one umbrella of central test. Interview is conducted for further digging out the hidden traits. Its absence in Pakistan and Bangladesh let the most of unwanted entries into the profession. Bhutan, Nepal and Sri -Lanka do have this test but its quality is not at par to India. So, overall Indian admission procedure is the best.

Total duration of the Elementary Teachers' Education Program is generally shorter than 
recommended by experts. The maximum shortage is seen in Nepal and Bangladesh. Minimum shortage is seen in the B. Ed Program launched by Royal University of Bhutan, Colombo University of Sri Lanka and University of education, Pakistan.

Shortage either minimum or maximum has direct impact on constituents' supplementary component. It is the reason that in all countries the duration of practical component (Teaching Practice and Apprenticeship) is shorter than recommended by experts. All tried to supplement the duration shortage of Teaching Practice with enhanced period of Apprenticeship.

Regarding other components, every country knows best about internal situation of its territory, student's achievement level \& background, political stability, prevailing policies, future goals and aspirations. Whatever proportion of various components is operating is the most suitable to their needs, so there is no comment. However, maximum match to criteria is seen in Bhutan, Sri -Lanka and Pakistan. Minimum matching is seen in Bangladesh.

Academic qualification of all SAARC Countries teaching staff is up to the mark. Professional aspect of teaching faculty is week in Maldives \& Pakistan. General education of administrators (principal, deans, and directors) is appropriate in the targeted institutions but generally it is below the criteria. Proportion of trained faculty and post graduate faculty in Bhutan, Bangladesh, Maldives and Pakistan is also below the criteria. Proportion of Professionally trained faculty to full faculty is weak in Maldives and Pakistan as compare to other sister states.

Bangladesh, Bhutan, Maldives and Nepal have scarcity of supplementary and Textual material. I.T (software as well as hard ware) \& ICT resources are up to the mark everywhere except Bangladesh, Bhutan, Nepal and Sri-Lanka.

All SAARC countries have included this subject in curriculum and they have provided required resources (software and hardware) for the good result. Under information Technology, Microsoft office package has been introduced one way or the other. Power point presentations allotted projects, Seminars, Mock teaching give ample chances to practice \& implant the acquired knowledge of technology.

All SAARC countries have Accreditation council to act as watchdog and coordinator among different agencies but their life span is quite different among them, so depending upon their life time quality of role played is different. In Pakistan, norms and standards, given need time to be implemented. In India, it started functioning in 1986.

Generally, curriculum is imparted in mother tongue except in India and Bhutan, who use English as medium of instruction. There is at least one revision of curriculum in last 5 year. B. Ed curricula belonging to University of education, Maldives College of higher education was designed recently but of Punjab University is very old and needs revision if not discarded.

In all SAARC countries, it is nominal compulsory activity conducted in an undesirable way without letter and spirit. Though its session starts everywhere after exam except Bhutan and Sri-Lanka where situations vary widely with availability. 
Again its spread is not over the whole day. Roughly, half of the routine daily working time, is wasted. Lessons delivered daily by students are almost half of the scheduled timetable of a teacher. India, here have put forth a system that gives output better than criteria. It is so because normal length of the day at Delhi University is 8 hours so students get ample time to practice teaching

Who will supervise is also adhoc based decision. All, except India, let the college teacher to be the supervisor also. All ignore the importance of co-operate school senior subject specialist .They do not have any criteria to evaluate the practice session even if it is available, e.g. India, they hardly use it.

There is no check and balance over the supervisors and students burnout. Some supervisors are very busy. They receive a lot of students other may have only few. Number of lesson a supervisor will supervise and the time s/he will spend in each observation session is not fix.

There is even no control over supervisor's activities. Normally, they write comments like good, very good, keep it up, excellent, improve etc over the lesson plan and give verbal remark in the observation session. According to the students, they learn more from the peers than anybody else.

The above mentioned issues are applicable to all countries. However, in India, the supervisor's activities are somewhat more controlled than others due to sound policies. Bhutan's system is also fine because of being a small, under better and organized control.

All SAARC countries attempted and still attempting to prepare diverse paper that boosts intellectuality and discourage cramming. Hit and trial style is hit very hard by all countries. The result shows that countries are improving their tools of evaluation.

The exam is generally consist of few long and short questions having no alternatives or optional. They are taken from the whole curricula without any specific foci.

The available data showed that all countries producing a well balanced paper, having both subjective type (long) and (short) objective type of questions. Other types used in exams are used at a smaller fraction and in the internal tests only.

\section{General Recommendation}

1. Bangladesh and Pakistan must upgrade the score for admission. If Supply seems to be upset in this way then better incentive will serve the purpose. In this regard, following incentives are recommended. Job availability and security, carrier growth, scholarship during study, better in and end service benefit. These benefits include benevolent fund, gratuity, pension, free housing \& medical allowance. Discretionary powers during the job like distribution of fund etc. Head of dispute settle committee.

2. Bangladesh, Maldives and Pakistan must introduce some kind of written external or internal test. To reduce political interference, a combination of both are recommended

3. Attempt should be made to check the student aptitude, Commitment to profession. 


\section{Macrothink}

4. Comprehension, arithmetic and linguistic capabilities must be examined.

5. More organized use of the time is recommended. It may be by preparing subject specialist or enhanced apprenticeship.

6. Stronger criteria and powerful entry test may provide an opportunity to teachers to teach the new competencies and not to repeat the old, already learnt, again and again.

7. Curriculum component's composition should be flexible enough that it can coordinate and compensate the stakeholder's previous knowledge and aspirations

8. Arrangements for the staff development and their carrier growth should be made.

9. Ample resources should be provided to run the curriculum effectively.

10. Actives of pupil Teachers and supervisors should be monitored and organized with the help of evaluation sheets.

11. Construction of the examination question should be such that only those students get through, who have mastery over the subject knowledge and professional competency.

\section{Pakistan specific Recommendation}

1. Throughout the region, Pakistan is the only country, where multiple Elementary Teachers' education Programs with the minor differences are operating. It is strongly recommended that there should be one and only uniform program that operates throughout the country.

2. In areas of high demand and less supply, a relaxation in admission criteria and procedure may be given. But otherwise, in general there should be a strong uniform policy of admission

3. Pakistan should develop strong admission criteria and design of admission procedure. In it interview, written and oral test must be administered to have better lot of students.

4. Duration of the program in Pakistan is too short to address the consumers concerns and meet the needs of the global market. University of education initiatives for optimum use of available time and increased duration of apprenticeship is worth following for parallel private and public operating programs in Punjab and other part of the country.

5. Bhutan, Nepal and Sri Lanka have special geographical issues that demand all rounder type of teacher. That is why we see stress to stage specialization component and enhanced duration. Pakistan, unlike these, has been gifted with smooth territories with excellent environmental condition. So, the schools are not lacking students. In this case, our focus should be Subject specialist with specialization in one or two subjects and not the all rounder types of teachers. This will cover the duration shortage problem 


\section{Macrothink}

Journal of Public Administration and Governance ISSN 2161-7104

6. Depending upon the countries, individual needs \& philosophy remarkable difference is seen in courses construction and curriculum composition. Every country should look this in its own perspective. Curricula of B. Ed program offered by University of Education are very much near to criteria than sister institutes. So, this difference should not be taken as significant. The motto should remain further progress.

7. College teachers' exemptions from Teacher education impact of training on students' achievement after the first five year, financial issues support the idea that even with short duration of the program marvellous result can be achieved. In this case, the training should be focused, blended with technology, and skill oriented.

\section{BIBLIOGRAPHY}

UNESCO, (1999) The Dakar Frame work for Action-2000

Jamil, Baela R. (2004). Teacher Education in Pakistan: A (Draft) Position Paper, presented at the National Conference on Teacher Education, December 20, 2004. Islamabad, hosted by the Academy for Educational Development

Mr. Muhammad Memon, Director of Institute of Educational Development at Agha Khan University, Concluding remarks at the first ever national conference "Teacher Education"

Memon. Muhammad, Director of Institute of Educational Development at Agha khan University Concluding remarks at the first ever national conference "Teacher Education"

World Conference on "Education for all” Jomtein .Thailand, 5-9 March, 1990.p2

Planning Commission (June 1994), "Eighth Five-Year Plan 1993-98" Govt. of Pakistan, Islamabad P. 313-14

Planning Commission (1989) "Seventh Five-Year Plan 1988-93 \& perspective Plan1988-2003”, Islamabad, Govt. of Pakistan P. 250

Ibrahim Imran (2000), Education Guide of Pakistan (1999-2000), Ibrahim Publisher, Lahore. $P-2$

Rudina Xhaferri \& Khalid Iqbal (From Dawn Lahore, Sunday, April 27,08)

Warwick, Donald P. and Fernando M. Reimers,(1991). Good Schools and Poor Schools in Pakistan

Khadija Haq (2000), Human Development South Asia 2000, Oxford University Press, U.K

Mahbub-ul-Haq \& Khadija Haq, (1988), Reflections on Human Development, Human Development Centre. Oxford University Press Karachi

Mahbub ul Haq, Khadija Haq,(1998), Human Development Centre. Oxford university press Karachi

Khan, Sughra Choudhry,(2004). From Practice to Policy: Making a Difference. Report prepared for the Teachers' Resource Centre. Karachi, Pakistan 
Khan Amir, (Jan, 2004), Free education, another official claim. School Life, Vol Jan, 2004

T.S.SODHI (1983). A Text book of Comparative Education, VANI Educational Books Vikas Publishing House PVT LTD p 272-275

UNESCO (1984), Diagnostic Study on Education Management. Regional Office for Education in Asia \& the Pacific Bangkok P1

UNESCO Statistical Year book1988, Paris Pg 91

UNESCO, (1995) WORLD Education Report, oxford: UNESCO Publisher.

UNESCO, (1999) The Dakar Frame work for Action-2000

UNESCO, (2000) EFA Planning guides 2001 Regional Offices for Asia and the Pacific 2001.

UNESCO, (2005) Human Development Report 2005,

UNESCO: (2006) Situation Analysis of Teacher Education in Pakistan :Toward a strategic Framework for Teacher Education and Professional Development

UNESCO (2008) Status of Teacher Education in Asia Pacific Region P 26

UN Inter -Agency Mission on basic Education (1995). Challenges and opportunities: Basic education for all in Pakistan. New York: United Nation Report

V.C.Pandey, (2003) Education Planning and Human Development. Isha Book. Delhi ISBN81-8205-006-5

Ministry of HRD, education and Cultural Affairs, (2002) annual School Census-2002 MHRDECA

Ministry of Education (1959), "Report of the Commission on Education" Govt. of Pakistan, Karachi

Ministry of Education, “Third Five Year Plan of India 1961-66”, Govt. of Pakistan, Islamabad p. 573

Minister of Information \& Broadcasting Islamabad, SAARC (South Asian association for Regional Cooperation Third summed of heads of state or Government Katmandu, 2-4 November 1987. p17

Ministry of Education (1966), "Report of India's Education Commission (1964-66)" Govt. of India

Ministry of Education and Scientific Research, (1969) "Proposal for New Education Policy", Govt. of Pakistan, Islamabad

Ministry of Education, (1972) “The Education Policy” Govt. of Pakistan, Islamabad

Ministry of Education, (1979) "National Education Policy and implementation Programme" Govt. of Pakistan, Islamabad 


\section{Macrothink}

Journal of Public Administration and Governance ISSN 2161-7104 2012, Vol. 2, No. 1

Ministry of Education (1986) “Indian National Education Policy on Education 1986”, Govt. of India

Ministry of Education (1990) "National Education Policy, 1998-2010", Govt. of Pakistan Islamabad $\mathrm{p} 48$

Ministry of Education (Dec 2001) "Education Sector Reform, strategic Plan (2001-2004)", Govt. of Pakistan Islamabad

Ministry of Finance, “Economic Survey (1986-87)", Economic Adviser's Wing, Govt. of Pakistan Islamabad,

Ministry of Education (Aug 2004), "The Development of Education", National Report Sri Lanka. p 10

National Academy for Primary Education (EPAN).2001, Certificate in Education(C-in-Ed) curriculum (Revised) for primary Teachers Training Mymen singh Bangladesh 157pp

National council for Teacher Education, Notification No F.49-4/2006-NCTE (N\&S) dated 30th, November 2006

Royal Government of Bhutan, Ministry of Education (2005) National Report on the Development of Education pg 1

World Bank (2005),"Treasure of the education system in Sri Lanka,"June30.

Ch Mehta, (2006), Investment in Education and its Impact on Human Resources. TALEEME ZAWEAY vol.17 pp40-44

Santosh Mehrotra (Editor) (2006) The Economics of elementary education in India New Delhi, Saga ISBN 81-7829-562-8.

Rivkin, S.G., E.A. Hanushek, and J.F. Kain. (2005): "Teachers, Schools and Academic Achievement Econometric a 73(2): Pp 417-58

Munawar. S .Mirza, (2007) DESD and Teacher Education Curricula in Pakistan, a paper presented at Thailand

Dr. N. Ramnath Kishan (editor) (2007) Global trend in Teacher education APH Publishing Corporation. 5 ANASARI Road, Darya Ganj New Delhi. 110002 P173

Feden D.Preston, Vogal Robert M (2003), Method of Teaching. New York: McGraw hill.

Charles F. Gritzner (2008), Concise Earth The World Atlas (2008), Millennium House Pty Ltd. 52 Bolwarra Road. Elanora Heights NSW 2101 Australia ISBN: 978-1-921209-12-3

Arends, Richard I (2004), Learning to Teach. New York: McGraw hill.

Aggerwal J.C (2004), Teacher and Education in Developing Society. Vikas Publishing House Pvt (Ltd), New Delhi. 